\title{
Use of eye care services by people with diabetes: the Melbourne Visual Impairment Project
} Catherine A McCarty, Conrad W Lloyd-Smith, Sharon E Lee, Patricia M Livingston,
Yury L Stanislavsky, Hugh R Taylor time. This compares with $28(43 \%)$ reported dilated fundus examinations in the 65 people who had seen an optometrist in the past 2 years. This finding is statistically significant $\left(\chi^{2}=10.2,1 \mathrm{df}, \mathrm{p}<0.005\right)$. Conclusion-These results indicate that nearly half of people with diabetes in Melbourne are not receiving adequate screening or follow up for diabetic retinopathy, despite universal health care.

(Br f Ophthalmol 1998;82:410-414)

Vision loss associated with diabetes is largely preventable with timely detection and treatment of diabetic retinopathy. Despite this, diabetic retinopathy remains a leading cause of blindness in Australians. There are about 350000 people known to have diabetes in Australia and possibly another 350000 who have not been diagnosed. ${ }^{1}$

Nearly all people with diabetes develop diabetic retinopathy within 20 years after diagnosis and approximately $10 \%$ of people with type II diabetes may have retinopathy at the time of diagnosis. ${ }^{2}{ }^{3}$ There is a high rate of vision loss due to diabetic retinopathy when diabetes has been present for more than 30 years, with approximately two thirds of people having lost vision after 35 years of diabetes. ${ }^{4}$

Current treatments, if appropriately timed and rigorously applied, may be effective in preventing up to $98 \%$ of severe visual loss and blindness due to diabetic retinopathy. ${ }^{5-8}$ This emphasises the need to ensure that individuals with diabetes receive adequate screening and are offered timely treatment. Recommendations in Australia are for people with diabetes to have a dilated pupil examination at least every 2 years. People with signs of diabetic retinopathy, if not already seeing an ophthalmologist, should be referred to an ophthalmologist for further management. ${ }^{9}$

Prompt and effective delivery of ophthalmic care to people with diabetes not only reduces personal suffering caused by blindness but also yields substantial cost savings. Previous studies have shown that the costs of providing preventative eye care are much less than the costs involved with providing support for a subsequent disability. ${ }^{10-12}$

Studies from the United States have shown that current recommendations for periodic screening for diabetic retinopathy are not well adhered to. ${ }^{13-15}$ However, little research has been done in Australia to determine whether people with diabetes receive regular eye examinations in accordance with recommendations. Our recent study showed that most general
Accepted for publication 10 October 1997 in the past 2 years, $48(71 \%)$ reported a dilated fundus examination during that 
Table 1 Diabetic retinopathy classification

\begin{tabular}{|c|c|}
\hline Grade & Signs \\
\hline Non-proliferative & $\begin{array}{l}\text { Retinal microaneurysms } \\
\text { Occasional blot haemorrhages } \\
\text { Hard exudates }\end{array}$ \\
\hline Pre-proliferative & $\begin{array}{l}\text { Venous beading } \\
\text { Large retinal blot haemorrhages } \\
\text { Cotton wool spots } \\
\text { Multiple intraretinal microvascular abnormalities }\end{array}$ \\
\hline Macular oedema & $\begin{array}{l}\text { Retinal thickening within } 2 \text { disc diameters of centre of macula } \\
\text { Adjacent hard exudates if associated with retinal thickening }\end{array}$ \\
\hline Proliferative & $\begin{array}{l}\text { Neovascularisation of the disc greater than } 1 / 4 \text { to } 1 / 3 \text { disc area } \\
\text { Vitreous or preretinal haemorrhage associated with neovascularisation } \\
\text { Neovascularisation of the retina } 1 / 2 \text { of disc area or more in size }\end{array}$ \\
\hline
\end{tabular}

practitioners do not examine the fundus of their patients with diabetes, but usually refer them to an ophthalmologist. ${ }^{16}$

The purpose of this study was to assess the use of eye care services in a representative sample of the Melbourne population aged 40 and over, comprising people with and without diabetes. Compliance with current guidelines for ophthalmic examination among the participants diagnosed with diabetes was evaluated.

\section{Methods}

THE MELBOURNE VISUAL IMPAIRMENT PROJECT The assessment of eye care service utilisation in Melbourne and the relation of this to diabetic status was investigated as part of the Melbourne Visual Impairment Project (Melbourne VIP). Details of the methods have been reported previously and only a summary will be included here. ${ }^{17}$ The Melbourne VIP is a large population based epidemiological study designed to determine the distribution and determinants of eye disease, to investigate the impact of visual impairment on an individual and their activities of daily living and to examine the use of and barriers to current eye healthcare services including the need for and accessibility of these services. Nine metropolitan suburbs of Melbourne, each consisting of two adjacent census collector districts were randomly selected for the Melbourne VIP. Eligible residents were identified by private household census and those permanent household members aged 40 or older were classed as eligible. The Royal Victorian Eye and Ear Hospital human research ethics committee approved the study and informed consent was obtained from all participants.

A screening questionnaire was initially administered to identify households with eligible residents. Repeated visits were made to the home when respondents were not available. Eligible residents were asked some basic demographic details and were invited to attend an eye examination at a local temporary test site for a more comprehensive interview and ophthalmic examination. If residents were

Table 2 Diabetic retinopathy prevalence in people with diabetes

\begin{tabular}{lll}
\hline & Number & $\%$ \\
\hline None & 125 & 77.2 \\
Non-proliferative & 21 & 13.0 \\
Pre-proliferative & 4 & 2.47 \\
Macular oedema & 7 & 4.32 \\
Proliferative & 5 & 3.09 \\
Total & 162 & \\
\hline
\end{tabular}

unable to attend the test site owing to some physical condition, a modified home visit was offered to obtain as much information as possible. Trained interviewers conducted the personal household interviews.

HISTORY OF USE OF EYE CARE SERVICES PROVIDED Basic demographic and health service utilisation data were collected during the initial private household interview including details on the use of eye care services. Respondents were initially asked if they had noticed a change in their vision in the past 10 years. If they had, they were then asked if they had seen someone about it and, if so, who they had visited. If an optometrist or ophthalmologist was not included in their response, and for those who had not noticed a change in their vision, they were then asked specifically if they had ever seen an optometrist or an ophthalmologist. The year of the last visit to an optometrist and/or ophthalmologist was recorded. An explanation of the terms optometrist and ophthalmologist was given to participants where necessary. In Australia an ophthalmologist is medically qualified and is specifically trained to diagnose or treat eye disease whereas optometrists are specialists in the area of refraction and cannot diagnose or treat eye conditions such as cataract, age related macular degeneration, or glaucoma.

For the last four test sites, people who reported a previous diagnosis of diabetes were asked if they had ever had the back of their eye examined and if so who performed the examination and when it was last performed. People with diabetes who had been examined at the first five test sites were subsequently contacted by telephone and asked the same question.

\section{HISTORY OF DIABETES}

A comprehensive interview was performed at the test site to elicit information that included past medical history and medication use ${ }^{17}$ One component of this interview elicited a previous diagnosis of diabetes. If a previous diagnosis of diabetes was reported, details were obtained on the year of diagnosis and on any medication either currently or previously taken for more than 12 months. For each medication taken, the type and number of years of use were recorded. The questions relating to diabetes and diabetic retinopathy have been validated and employed by Welborn et al. ${ }^{18} 19$

\section{FUNDUS EXAMINATION}

The clinical examinations were performed by one of the co-authors (YLS). Pupils were dilated with one drop of tropicamide $(0.5 \%)$ and one drop of phenylephrine hydrochloride $(10 \%) .{ }^{17}$ Ophthalmic examination of the fundus was performed with a slit lamp and 90 dioptre convex lens and supplemented by indirect ophthalmoscopy if peripheral abnormalities were revealed or suspected. Presence or absence of diabetic retinopathy was recorded. If diabetic retinopathy was detected, the eyes were clinically classified as having nonproliferative or pre-proliferative retinopathy, 


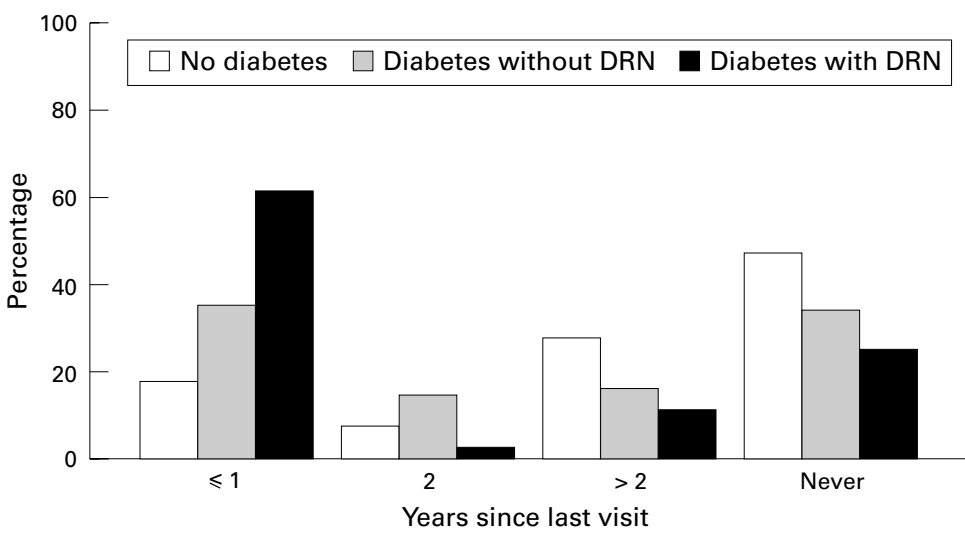

Figure 1 Years since last visit to an ophthalmologist by diabetes/diabetic retinopathy (DRN) status.

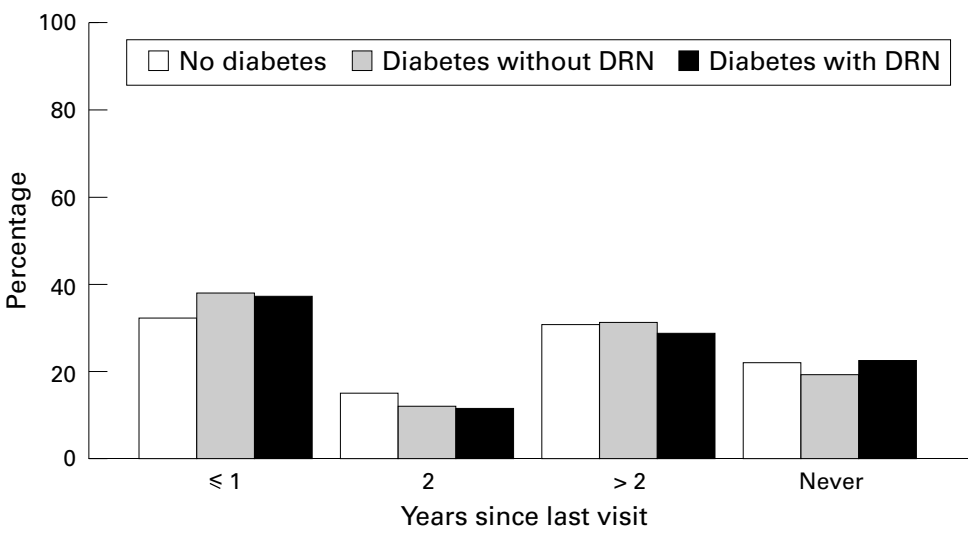

Figure 2 Years since last visit to an optometrist by diabetes/diabetic retinopathy (DRN) status.

macular oedema, or proliferative retinopathy based on a shortened version of the classification system adopted by the American Academy of Ophthalmology ${ }^{20}$ (Table 1).

VISION ASSESSMENT

Presenting and best corrected distance visual acuity were measured using the ETDRS (Early Treatment of Diabetic Retinopathy) letter chart. ${ }^{17}$

\section{ANALYSIS}

Knowledge of diabetes status and clinical fundus examination were required for inclusion in subsequent analyses. The worse of the two eyes was used for classification of diabetic retinopathy status.

For the analyses, participants were divided into the following mutually exclusive groups: (1) people with diabetic retinopathy, (2) people with diabetes and no diabetic retinopathy, and (3) people without diabetes. They were also categorised as having seen or not seen an optometrist, an ophthalmologist, or both. Within these categories they were grouped by

Table 3 Ophthalmic and optometric examination by diabetes status

\begin{tabular}{lllll}
\hline & Diabetes & No diabetes & $\chi^{2}$ & p Value \\
\hline Ever visit? & $107 / 157(68.2 \%)$ & $1593 / 2973(53.6 \%)$ & 12.8 & 0.001 \\
$\quad$ Ophthalmologist & $127 / 158(80.4 \%)$ & $2332 / 2984(78.2 \%)$ & 0.44 & 0.51 \\
$\quad$ Optometrist & & & \\
Visit in past 2 years? & $82 / 156(52.6 \%)$ & $746 / 2933(55.6 \%)$ & 55.6 & 0.001 \\
$\quad$ Ophthalmologist & $76 / 154(49.4 \%)$ & $1369 / 2924(46.8 \%)$ & 0.38 & 0.54 \\
Optometrist & & & \\
\hline
\end{tabular}

the number of years since they had last seen an optometrist or ophthalmologist.

Paradox Version 4.0 (Borland International, Scotts Valley, CA, USA) was used for storage and processing of subject records. Statistical analyses were performed with sas Version 6.09. The statistical procedures used in this research are documented in SAS/STAT user's guide. ${ }^{21} \mathrm{~A}$ $\mathrm{p}$ value $<0.05$ was considered to be statistically significant.

\section{Results}

PARTICIPANT CHARACTERISTICS

A total of 3946 people were determined to be eligible. Of these, 3271 (83\%) attended the test site or were examined at home because of limited mobility. The non-participants were significantly more likely to speak a language other than English in their own home, but did not differ significantly in any other respects. ${ }^{22}$

In all, $3189(97.5 \%)$ people completed the full assessment required (knowledge of diabetes status and clinical fundus examination). Of the 82 with incomplete assessment, 10 people either did not participate in the interview or did not know if they had diabetes, six with diabetes did not have a fundus examination, and 66 without diabetes did not have a fundus examination. The reasons for no fundus examination were uncooperative behaviour, small pupils, or opaque ocular media. Of the 3189 people included in the analyses, $1482(46.5 \%)$ were males. The age of the participants ranged from 40 to 98 years, with a mean of 58.6 (SD 11.3).

A total of $162(5.07 \%)$ reported a previous diagnosis of diabetes. Only seven $(4.3 \%)$ were diagnosed with diabetes at or before the age of 30. The mean duration of diabetes since diagnosis was 9.15 years (range 0-57 years, SD 9.26); $119(73.5 \%)$ people with diabetes reported current medical treatment for their diabetes. For those 116 who could remember their treatment, $23(19.8 \%)$ reported using insulin and $93(80.2 \%)$ reported using oral hypoglycaemic agents. Diabetic retinopathy was detected in $37(22.8 \%)$ people with diabetes (Table 2). Everyone identified with diabetic retinopathy had a previous diagnosis of diabetes.

USE OF EYE SERVICES

People with diabetes were significantly more likely to have visited an ophthalmologist ever or in the past 2 years than people without diabetes (Table 3). However, almost one third of people with diabetes had never visited an ophthalmologist. The proportion of people who had never seen an ophthalmologist was $47.1 \%$ for those without diabetes, $34.2 \%$ for those with diabetes but without diabetic retinopathy, and $25 \%$ for those with diabetic retinopathy (Fig 1). Sixty one per cent of people with diabetic retinopathy had seen an ophthalmologist in the past year and a further $3 \%$ within the past 2 years. This distribution of attendance at an ophthalmologist varied significantly by diabetes and diabetic retinopathy status $\left(\chi^{2}\right.$ $75.8,6 \mathrm{df}, \mathrm{p}=0.001$ ). 
People with diabetes were not significantly more likely to visit an optometrist than people without diabetes (Table 3 and Fig 2). Overall, $37.7 \%$ of people with diabetes and $32.9 \%$ without diabetes had visited an optometrist within the past year $\left(\chi^{2}=2.25,1 \mathrm{df}, \mathrm{p}=0.13\right)$. The distribution of visits to an optometrist did not differ by diabetes or diabetic retinopathy status $\left(\chi^{2} 3.10,6 \mathrm{df}, \mathrm{p}=0.80\right)$.

Some estimates for the frequency of retinal examinations are also available. Information concerning retinal examinations was available for 135 individuals $(83.3 \%$ of people with diabetes). Only $74(54.8 \%)$ could recall ever having a dilated fundus examination; 10 (14\%) by an optometrist, $62(86 \%)$ by an ophthalmologist, and five (7\%) by a general practitioner. Of those 68 people who had seen an ophthalmologist in the past 2 years, 48 $(71 \%)$ reported a dilated fundus examination during that time. This compares with 28 $(43 \%)$ reported dilated fundus examinations in the 65 people who had seen an optometrist in the past 2 years. This finding is statistically significant $\left(\chi^{2} 10.2,1 \mathrm{df}, \mathrm{p}<0.005\right)$.

\section{Discussion}

These data indicate that nearly half of adults with diabetes in Melbourne are not receiving adequate 2 yearly screening for diabetic retinopathy. This is in contrast with our recent survey of general practitioners in which $88 \%$ of Victorian general practitioners reported referral of their patients with diabetes to an ophthalmologist at the recommended frequencies. ${ }^{16}$ The disparity in these results could be due to a reporting bias by the general practitioners, a breakdown in the referral chain, or a combination of the two.

Our results are generally consistent with findings from 2405 diabetic participants in the National Health Interview in the United States. ${ }^{13}$ Thirty four per cent of the people surveyed had not had a comprehensive eye examination, including pupil dilatation, in the past 2 years, and $20 \%$ had not had any eye examination during that time. No differentiation was made in that study between examination by an ophthalmologist or an optometrist. We might have expected to find higher rates of eye examinations in Australia than the United States because universal health care through Medicare exists in Australia. Provided patients visit public hospitals, they have no out of pocket expense for their retinal examinations in Australia. If they visit a private ophthalmologist and do not have private health insurance, they have to cover any gap in the scheduled Medicare fee and the amount billed by the ophthalmologist. Generally, the waiting time to see a private ophthalmologist is substantially less than to visit a public clinic.

Our results are also similar to those of the Wisconsin Epidemiological Study of Diabetic Retinopathy, which found that $50 \%$ of people with diabetes had not had an ophthalmic examination in the past 2 years. ${ }^{14}$ In the 10 year follow up of this study cohort, approximately $30 \%$ of people still had not had an eye examination in the last year. ${ }^{15}$ These results demon- strate that although treatment information has been available for many years, an appropriate level of care has still not been achieved.

Important characteristics of our study are that it is a population based, epidemiological study with a high response rate where a comprehensive eye examination has been performed on all participants, with and without diabetes, as well as collection of detailed information on the use of eye care services. The self reported $5.1 \%$ rate of diabetes in our study population is nearly identical to the rates reported in the 1989-90 National Health Survey in Australia. ${ }^{19}$ Researchers documented self reported rates of $2.91 \%$ in males aged $45-54$ to a rate of $8.74 \%$ in people over age 75 . These similarities further support the representativeness of our study population.

Only data on self reported diabetes have been collected in this study. There is estimated to be a high proportion of people in Australia with undiagnosed diabetes. ${ }^{18}{ }^{19}$ It is believed that there is one case of undiagnosed diabetes for every known case. ${ }^{1}$ These people would be even less likely to receive recommended eye examinations than people known to have diabetes. Therefore, our results probably overestimate the level of eye care received by the total population of adults who actually have diabetes.

Diabetic retinopathy status in our study was based on clinical assessment. Results from previous studies have shown good agreement between the methods of clinical assessment and fundus photography with a slight underestimation of diabetic retinopathy with clinical diagnosis. ${ }^{23} \mathrm{~A}$ recent study in Barbados found the prevalence of diabetic retinopathy by clinical grading was $7.7 \%$ compared with $8.7 \%$ with fundus photography. ${ }^{24}$

Primary prevention of diabetic retinopathy has been shown to be cost effective, ${ }^{10-12}$ but requires innovative public health strategies. Education of people with diabetes and their relatives is a key to encouraging more regular screening for diabetic retinopathy. People with diabetes must be made aware that early stage diabetic retinopathy can exist without visual symptoms and that early detection through regular dilated eye examinations can ensure timely diagnosis and treatment to preserve vision. Relatives of people with diabetes can help to encourage timely examinations.

Primary care providers play an important role in the coordination of care for people with diabetes. Greater continuity of patient care could be achieved if primary care providers regularly screened their diabetic patients for diabetic retinopathy or had a system in place to follow up on referrals made. Because people are more likely to see an optometrist than an ophthalmologist, it may be appropriate for optometrists to be more actively involved in screening people with diabetes for diabetic retinopathy. The use of a non-mydriatic camera to augment existing eye care services has also been suggested as a possible cost effective means of improving the screening rate for diabetic retinopathy among people with diabetes. ${ }^{232526}$ 
In conclusion, people with diabetes in Melbourne do not receive adequate screening for the detection of diabetic retinopathy. Collaboration between eye care specialists and primary care providers, together with improved patient awareness of the risks and consequences of developing diabetic retinopathy, is essential to ensure that people with diabetes receive regular eye examinations to prevent vision loss.

Each author declares that he or she has no proprietary interest in connection with this study.

The work described in this paper was partially funded by the Victorian Health Promotion Foundation, the National Health and Medical Research Council, the Ansell Ophthalmology Foundation, and the Dorothy Edols Estate.

1 McCarty D, Zimmet P. Diabetes 1994 to 2010: global estimates and projections. Melbourne, Australia: International Diabetes Institute, 1994.

2 Klein R, Klein BEK, Moss SE, et al. The Beaver Dam Eye Study: retinopathy in adults with newly discovered and previously diagnosed diabetes mellitus. Ophthalmology previously diagn

3 Mitchell P. The prevalence of diabetic retinopathy: a study of 1300 diabetics from Newcastle and the Hunter Valley. of 1300 diabetics from Newcastle

4 Klein R, Klein BEK, Moss SE. Visual impairment in diabetes. Ophthalmology 1984;91:1-9.

5 Ferris FL. How effective are treatments for diabetic retinopathy? fAMA 1993;269:1290-1.

6 Ferris FL. Issues in management of diabetic retinopathy. Hospital Practice 1993:79-89.

7 Rohan TE, Frost CD, Wald NJ. Prevention of blindness by screening for diabetic retinopathy: a quantitative assessment. BMF 1989;299:1198-201.

8 Agardh E, Agardh CD, Hansson-Lundblad C. The five-year incidence of blindness after introducing a screening programme for early detection of treatable diabetic retinopathy. Diab Med 1993;10:555-9.

9 Retinopathy Subcommittee of the Australian Diabetes Society for Diabetes Australia. Diabetes and the eye. Melbourne: Diabetes Australia, 1994 .

10 Javitt JC, Canner JK, Frank RG, et al. Detecting and treating retinopathy in patients with type I diabetes mellitus: a retinopathy in patients with type I diabetes mellitus:
health policy model. Ophthalmology 1990;97:483-95.
11 Javitt JC, Aiello LP, Bassi LJ, et al. Detecting and treating retinopathy in patients with type I diabetes mellitus: savings retinopathy in patients with type I diabetes mellitus: savings associated with improved implementation
guidelines. Ophthalmology 1991;98:1565-74.

12 Javitt JC. Preventative eye care in people with diabetes is cost-saving to the federal government: implications for health care reform. Diab Care 1994;17:1-10.

13 Brechner RJ, Cowie CC, Howie J, et al. Ophthalmic xamination among adults with diagnosed diabetes mellitus. $\mathcal{F} A M A 1993 ; 270: 1714-18$

14 Witkin SR, Klein R. Ophthalmologic care for persons with diabetes. $\mathcal{F} A M A$ 1984;251:2534-7.

15 Moss SE, Klein R, Klein BEK. Factors associated with eye examinations in persons with diabetes. Invest Ophthalmol Vis Sci 1994;35:1141.

16 Dickson PR, McCarty CA, Keeffe JE, et al. Diabetic retinopathy: examination practices and referral patterns of retinopathy: examination practices and referral pa

17 Livingston PM, Carson CA, Stanislavsky YL, et al. Methods for a population-based study of eye disease: the Melbourne Visual Impairment Project. Ophthalmic Epidemiol 1994;1: 139-48.

18 Welborn TA, Glatthaar C, Whittall D, et al. An estimate of diabetes prevalence from a national sample: a male excess. Med $\mathcal{F}$ A ust 1989;150:78-81.

19 Welborn TA, Knuiman MW, Bartholomew HC, et al. 1989-90 National Health Survey: prevalence of selfreported diabetes in Australia. Med f Aust 1995;163:12932.

20 American Academy of Ophthalmology Quality of Care Committee Retina Panel. Diabetic retinopathy-preferred practice patterns. San Francisco: American Academy of practice patterns. San

21 SAS/STAT user's guide, Version 6, Fourth Edition. Vols 1 and 2. Cary, NC: SAS Institute Inc, 1989.

22 Livingston PM, Lee SE, McCarty CA, et al. A comparison of participants with non-participants in a population-based epidemiologic study: the Melbourne Visual Impairment Project. Ophthalmic Epidemiol 1997;4:73-81

23 Peters AL, Davidson MB, Ziel FH. Cost-effective screening for diabetic retinopathy using a non-mydriatic retinal camera in a prepaid health care setting. Diab Care 1993;16: 1193-5.

24 Schachat AP, Hyman L, Leske CM, et al. Comparison of diabetic retinopathy detection by clinical examinations and photograph gradings. Arch Ophthalmol 1993;111:1064-70.

25 Klein R, Klein BEK, Neider MW, et al. Diabetic retinopathy as detected using ophthalmoscopy, a nonmydriatic camera and a standard fundus camera. Ophthalmology 1985;92: 485-91.

26 Williams R, Nussey S, Humphry R, et al. Assessment of non-mydriatic fundus photography in detection of diabetic retinopathy. BMF 1986;293:1140-3. 